\title{
A DISCUSSÃO DO MOVIMENTO ANTIVACINA PARA UMA FORMAÇÃO CRÍTICA: IMPLICAÇÕES NO ENSINO DE CIÊNCIAS ATRAVÉS DAS CONTROVÉRSIAS SOCIOCIENTÍFICAS
}

\author{
The Anti-Vaccine Movement Discussion Toward a Critical Formation: Implications of \\ the Teaching of Science by Means of the Social-Scientific Issues
}

\author{
Eril Medeiros da Fonseca* \\ Leandro Duso ${ }^{* *}$
}

\begin{abstract}
Resumo: O movimento antivacina atualmente tem sido discutido de forma ampla em diversos setores da sociedade, e muitas informações são difundidas sem uma problematização maior sobre suas implicações. No âmbito dos currículos escolares, essas questões estão envolvidas em debates sobre o desenvolvimento da Ciência e Tecnologia (C\&T). Já no Ensino de Ciências, aspectos controversos acerca de determinados temas podem ser problematizados por meio das controvérsias sociocientíficas (CSC). Assim, busca-se discutir, no contexto do Ensino de Ciências crítico, as contribuições das CSC nas implicações do movimento antivacina que o Brasil está vivenciando. Alguns parâmetros sobre as implicações do movimento antivacina foram associados para aprofundar as discussões, dos quais: disseminação de informações e atribuições da Ciência na sociedade; e determinismo político-econômico em detrimento de uma formação crítica. Entende-se ser pertinente a discussão dessas questões em processos educativos devido às consequências de saúde pública/coletiva, e associada à importância de uma leitura consciente da realidade. Tal formação pode ser viabilizada a partir da inserção de discussões sobre questões sociais na prática pedagógica do professor, como as CSC, tendo em vista, no entanto, que as controvérsias não se constituem como simples aporte metodológico, mas como estratégia que permite a articulação de uma formação crítica.
\end{abstract}

Palavras-chave: Ensino de Ciências. Ciência e Tecnologia. Questões sociais.

Abstract: The anti-vaccine movement has currently been widely discussed in many sectors of society, and much information is spread without a bigger problematization of its implications. In the context of school curricula, such issues are involved in debates on Science and

\footnotetext{
* Licenciado em Ciências da Natureza. Especialista em Ensino de Ciências na Educação do Campo e Mestre em Ensino pelo Programa de Pós-graduação em Ensino da Universidade Federal do Pampa. Possui interesse na área de Ensino com ênfase nas seguintes temáticas: contextualização, formação de professores, abordagem de temas (Educação CTS, articulações entre CTS/PLACTS-Freire), currículo e processos de ensino e aprendizagem de Ciências. Orcid: https://orcid.org/0000-0001-9529-2357. E-mail: erilmf@gmail.com.

** Doutor em Educação Científica e Tecnológica pelo Programa de Pós-graduação em Educação Científica e Tecnológica da Universidade Federal de Santa Catarina. Lidera o grupo de pesquisa "A Ponte: interligando a educação básica e o ensino superior no Ensino de Ciências e Biologia". Atua na linha de pesquisa de formação de professores, Educação CTS, Controvérsias sociocientíficas no ensino de Ciências e Biologia e articulação universidade-escola. Professor do Departamento de Metodologia de Ensino da Universidade Federal de Santa Catarina, Orcid: https://orcid.org/0000-0002-2605-0829. E-mail: dusoleandro@ gmail.com.
} 

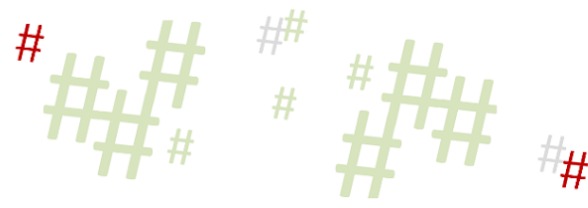

Technology (C\&T) development. Yet on Teaching Science, controversial aspects about certain issues may be problematized through the socio-scientific issues (SSI). Thus, the focus is of discussing, in the critical Teaching of Science context, the SSI contribution in the anti-vaccine movement implications that Brazil has been experiencing. A few parameters on the anti-vaccine movement implications were associated to deepen the discussions, amongst which: dissemination of information and attribution to Science in society; and political-economic determinism in detriment of a critical formation. It is comprehensible the importance of such discussions in teaching processes, due to the public/collective health consequences, and associated to the importance of a conscious reading of reality. Such information can be made possible from the insertion of discussions on social issues in the teacher's pedagogical practice, for instance the SSI, in view of, though, that the controversies do not constitute simply as a methodological contribution, but as a strategy that allows the articulations of a critical formation.

Keywords: Teaching of Science. Science and technology. Social Issues.

\section{Introdução}

A intervenção da tecnologia na sociedade em que vivemos é cada vez mais marcante, aliás, a maior parte dos mecanismos de produção possui uma influência tecnológica. Assim, é necessário articular uma formação que proporcione ao estudante a avaliação e posição diante de atividades que envolvam processos tecnológicos e científicos, como produção de cosméticos, produtos geneticamente modificados, entre outros.

O movimento antivacina, por exemplo, configura uma problemática presente atualmente e que hegemonicamente não é discutida ou seus aspectos não são problematizados de forma aprofundada. A exemplo dessa questão, dados divulgados pelo Ministério da Saúde (PENIDO, 2019) mostram que o Brasil registrou 2.753 casos confirmados de sarampo até setembro de 2019 , em treze estados brasileiros, o que significa um aumento em $18 \%$ no número de casos de sarampo no país. Esse movimento pode ter suas raízes na chamada "Revolta da Vacina", ocorrida no Rio de Janeiro por volta do início do século XX, em que houve uma reação popular à campanha de vacinação obrigatória na época. Essa vacinação em massa contra doenças como malária e febre amarela foi comandada pelo sanitarista Oswaldo Cruz e aplicada como parte de várias reformas e projetos de urbanização de forma imposta (PORTO, 2003). A própria diminuição e/ou erradicação de certas doenças também pode colaborar para a não adesão às vacinas. Assim, nesse contexto de aversão às vacinas, constitui-se o movimento antivacina, o qual tem disseminado a ideia contra a vacinação e, em alguma medida, ameaça o combate a doenças até então evitáveis por meio desse processo, como o sarampo e a poliomielite.

Abordar questões contemporâneas como o movimento antivacina, contribui, segundo Angotti e Auth (2001), para superar visões de Ciência enraizadas em pensamentos positivistas, que desprezam justamente a dimensão social, já que essa influencia a construção do conhecimento científico. Assim, algumas propostas para o Ensino de Ciências vêm sendo desenvolvidas (RAMOS; SILVA, 2007) para sala de aula do Ensino Fundamental e Ensino Médio com uma abordagem ampla, proporcionando ao estudante possibilidades de decisões públicas relacionadas à Ciência e Tecnologia (C\&T) ou, ainda, a busca por conhecimentos específicos para a compreensão e discussão de questões que envolvam a dimensão C\&T.

Daí a importância de articular processos que possam instrumentalizar os sujeitos a realizarem uma leitura coerente da realidade, para que, além de filtrar informações sobre o 
desenvolvimento científico e tecnológico, possam realizar escolhas, enquanto cidadãos. Nesse sentido, como parte de discussões mais amplas relacionadas a sentidos e significados da Ciência (RAMOS; SILVA, 2007), enquadram-se as controvérsias sociocientíficas (CSC). A discussão das controvérsias coloca-se no intuito de problematizar situações que envolvam C\&T em um momento histórico no qual a participação pública tem sido ausente em decisões tomadas quase que exclusivamente em nível governamental.

De certo modo, no âmbito dos currículos escolares, as questões sobre produção do conhecimento científico e posicionamento em debates sociais estão - ou deveriam estar envolvidas nos debates sobre processo e produto dos avanços da C\&T. No Ensino de Ciências, a utilização das CSC permite reunir argumentos para problematizar aspectos controvertidos sobre uma problemática real, que divide posicionamentos e possui interferência tanto de C\&T quanto de implicações sociais. Somado a isso, no contexto contemporâneo, essas controvérsias são influenciadas pelas mídias digitais, de forma geral.

Diante das implicações desse movimento contrário à vacinação, além da importância da abordagem de questões reais relacionadas à dimensão social, busca-se, neste trabalho, discutir as contribuições das CSC nas implicações do movimento antivacina que o Brasil está vivenciando, no contexto do Ensino de Ciências.

\section{As controvérsias sociocientíficas no ensino de Ciências}

Segundo Ramos e Silva (2007), a adoção, no Ensino de Ciências, de uma visão direta sobre C\&T, das relações entre desenvolvimento científico, tecnológico e social, contribui para um modelo linear/tradicional de desenvolvimento. Essa crença, para Auler (2018), consiste na ideia de que o desenvolvimento científico gera desenvolvimento tecnológico, que gera desenvolvimento econômico, o qual, por sua vez, determina o desenvolvimento social, ou seja, está relacionado ao bem-estar social. Há também uma compreensão de que o conhecimento científico ocupa uma posição superior a outros conhecimentos, possuindo determinado poder para resolver problemas apenas através de sua perspectiva. Esses discursos circulam amplamente na sociedade e, de acordo com Ramos e Silva (2007), também constituem práticas escolares, influenciando a seleção de conteúdos e organização dos currículos. Por isso, Auler (2011) argumenta sobre a necessidade de um currículo que potencialize a compreensão e participação em debates, temas sociais, marcados pela C\&T, já que os conhecimentos científicos e tecnológicos são vistos como inquestionáveis.

A inserção das CSC em práticas educativas de Ciências, em torno de temas sociais, pode abarcar discussões mais amplas sobre essas questões e, segundo Ramos e Silva (2007), trabalhar em relação aos sentidos da Ciência. Para Duso (2017), a utilização das CSC em Ciências tem sido recorrente em propostas curriculares relacionadas a temas que são concebidos em vertentes da Educação Ciência-Tecnologia-Sociedade (CTS), pois potencializam tanto a aprendizagem dos conteúdos conceituais quando a de processos de natureza científica, tecnológica, assim como o desenvolvimento cognitivo, social, político e ético.

Segundo Nelkin (1995), as CSC podem surgir de implicações sociais, morais ou religiosas ou a partir de uma prática científica, por tensões sociais entre direitos coletivos e individuais, valores ambientais e econômicos e, ainda, implicações quanto à saúde proveniente de aplicações tecnológicas, a exemplo do movimento antivacina, discutido aqui.

Dentre as várias definições para uma CSC, há alguns critérios, segundo Duso e Hoffmann (2013), para compor uma controvérsia: surgirem de impactos sociais de inovações científico-tecnológicas que dividem a sociedade em geral e a comunidade científica; permitirem 
discussões entre as partes envolvidas sobre uma controvérsia, expondo ideias e argumentações; e colocarem as pessoas divididas diante de uma problemática, de modo que a simples experiência ou vivência de vida impossibilitem a resolução.

Uma CSC releva diversos pontos de vista e, por isso, não pode ser facilmente resolvida. Quando envolve discussões éticas e morais e está relacionada a julgamento de grupos, não pode ser guiada somente por fatos (SANTOS et al., 2011). Por isso, para Santos et al. (2011), discutir as controvérsias no Ensino de Ciências não significa encontrar uma verdade moral ou científica, mas colocar os estudantes em situações favoráveis à análise de informações, construção de argumentos e de poder ouvir o outro.

De modo geral, o que se propõe com a abordagem das CSC é possibilitar espaços de discussão sobre questões sociais. Constituir uma sociedade democrática perpassa a participação efetiva de diversos setores sociais, por isso, são necessários processos formativos que contribuam para enriquecer (PEREZ et al., 2011) as ações de cidadania dos sujeitos. Afinal, assim como assinalam Reis e Galvão (2004), o futuro do conhecimento científico e tecnológico não pode ser responsabilidade apenas dos cientistas, governos ou especialistas.

\section{0 contexto da "Revolta da Vacina"}

Atualmente, têm sido frequentes os movimentos e grupos mobilizados no que se denominou de "movimento antivacina". Pode-se dizer que essas repercussões tiveram suas raízes em conflitos parecidos há algum tempo no Rio de Janeiro. No início do século XX, esse município sofria com condições precárias de saneamento básico e higiene, desencadeando focos de epidemias, como varíola e febre amarela.

Nessa época, ocorreram diversas manifestações populares e polêmicas, ficando conhecidas como "Revolta da Vacina". Segundo Porto (2003), durante esse período, Oswaldo Cruz - sanitarista - foi responsável pela estruturação da saúde pública no Brasil. A população revoltou-se contra o plano de saneamento implantado, mas, acima de tudo, com a remodelação urbana. Essa medida, segundo a autora, realizou intervenções drásticas para combater as epidemias. Foram demolidos cortiços e casebres de vários bairros, dando espaço a grandes avenidas. Fez-se o alargamento das ruas e os moradores foram desalojados, refugiando-se em barracos em morros/bairros distantes, constituindo as periferias. Além disso, dentre a população em geral, havia uma desconfiança em relação à vacina. A população acreditava que ela poderia matar ou causar modificações físicas, como deixar a face da pessoa com forma parecida de um bezerro. Essas falas emergiram devido ao fato de as primeiras vacinas antivariólicas terem sido preparadas com fluidos extraídos de lesões de vacas com a vaccínia, a varíola bovina (SCLIAR, 2002).

Em 1904, o município do Rio de Janeiro foi atingido por uma epidemia de varíola. Oswaldo Cruz, sabendo da resistência à implantação das vacinas, organizou uma expedição ao estilo militar, tornando a vacinação obrigatória (PORTO, 2003). Com isso, as brigadas sanitárias entravam nas casas à força, causando certo temor na população em vacinar-se. A maior parte do povo ainda desconhecia e também receava os efeitos que a injeção de líquidos até então desconhecidos poderia causar no organismo humano. A repulsa intensificou-se com o apoio de grupos contrários ao governo da época, e praticamente toda a imprensa impugnou Oswaldo Cruz. Tudo culminou com um motim popular em que bondes foram incendiados, lojas saqueadas e, durante uma semana, o município do Rio de Janeiro viveu uma verdadeira guerra civil. Em novembro de 1904, a obrigatoriedade da vacinação foi suspensa, sendo que, em 1908, eclodiu um novo surto com mais de 10 mil casos (PORTO, 2003). 
Segundo Sevcenko (2003), os grupos opositores à vacinação temiam os métodos de aplicação de vacina e sentiam-se intimidados por aplicadores, enfermeiros e fiscais. Esses grupos de opositores eram pouco confiáveis, já que agiam com brutalidade e tinham uma moralidade duvidosa, atitudes que já eram conhecidas em uma campanha anterior de combate à febre amarela. Apesar disso, o autor argumenta que tais grupos defendiam que, se o governo acreditava na qualidade das vacinas,

[...] que deixasse a cada consciência a liberdade de decidir pela sua aplicação ou não, podendo, inclusive, escolher as condições que melhor lhe conviessem para recebê-la. Obstavam, enfim, não contra a vacina, cuja utilidade reconheciam, mas contra as condições da sua aplicação e acima de tudo contra o caráter compulsório da lei (SEVCENKO, 2003, p. 07).

Para Mattos (2005), essa revolta diz respeito a um processo de apropriação do corpo de Ciência. Com isso, a população revoltosa reivindicava não apenas contra as ações autoritárias ou perda das moradias, mas também pela perda do controle de seus próprios corpos. Nesse contexto, o combate à varíola representava um avanço da Ciência, um progresso ao qual a população tentava resistir.

Entende-se que essa resistência está relacionada ao acesso à informação e ao processo de construção do conhecimento científico. Atualmente, pode-se dizer que há movimentos análogos à "Revolta da Vacina", ainda que sejam contextos e épocas distintos. Esses aspectos contribuem para problematizar algumas visões já naturalizadas em nossa sociedade, como a ideia de que, quanto mais tecnologia, tem-se mais informação, e quanto mais informação, mais conhecimento se possui. Tais visões aproximam-se ao que Auler (2007) aponta como mitos envolvendo construções históricas como o determinismo tecnológico. Com isso, alguns questionamentos fazem-se pertinentes: os conhecimentos envolvendo processos científicotecnológicos produzidos e repassados como verdades conseguem suprir demandas sociais? Em que medida os processos educativos proporcionam uma formação para uma leitura crítica sobre diversos acontecimentos sociais? Tais indagações norteiam as discussões realizadas a seguir por meio das CSC e a história da ciência, envolvendo o movimento antivacina.

\section{Abordagem do movimento antivacina através da discussão das CSC}

Conforme apontado anteriormente, os movimentos relacionados a discursos contra a vacinação vêm se intensificando, especialmente de modo virtual, como as redes sociais. Diante disso, assim como apontam Fonseca, Duso e Hoffmann (2017), são necessários espaços formativos, sejam escolares ou não escolares, que permitam discutir as relações entre Ciência, Tecnologia e Sociedade, como as implicações das CSC na discussão do movimento antivacina. Por isso, adotam-se as CSC, aliadas à história da ciência, como estratégia de ensino para ambientalizar a discussão e reflexão em relação à tomada de decisão de forma crítica sobre essa temática.

Através dessa proposta, é possível que o educando perceba que a aceitação ou o ataque a algum parecer não depende apenas de seu valor intrínseco e de sua fundamentação, mas que também, nesse processo, estão envolvidas outras forças, tais como: sociais, políticas, filosóficas ou religiosas. 
A abordagem da História e Filosofia da Ciência, juntamente com a discussão das CSC, procura trazer para o ensino debates no campo dos estudos sociais da ciência, caracterizados em três esferas, segundo Beltran, Saito e Trindade (2014), demonstrados na Figura 1:

Figura 1 - Articulação entre História e Filosofia da Ciência e CSC

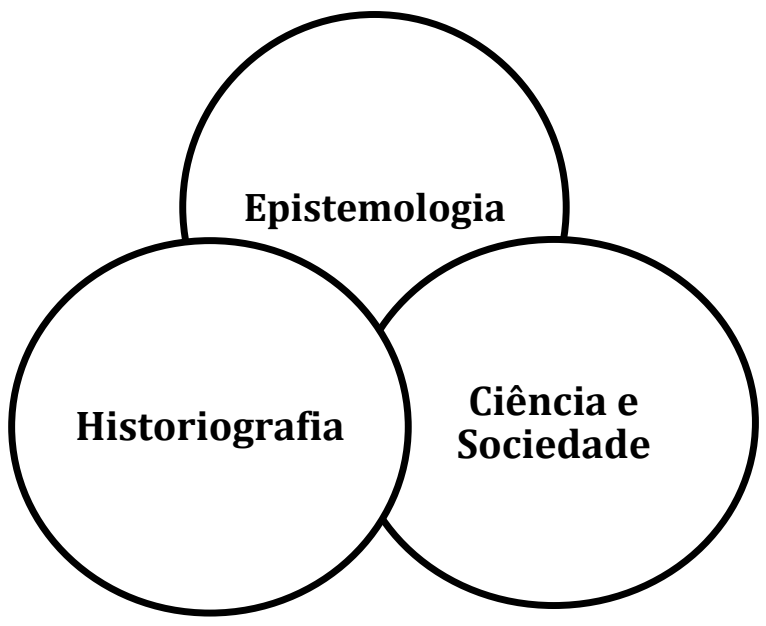

Fonte: Beltran, Saito e Trindade (2014, p. 17).

O ensino acerca da natureza da Ciência (especialmente sobre os enquadramentos sociais, institucionais e políticos no interior dos quais a Ciência opera) encoraja os alunos a apreciarem a Ciência como um empreendimento humano com história, aventuras, personalidades, dramas, disputas, controvérsias, criatividade, normas e princípios éticos (DRIVER et al., 1996).

Foram associados alguns parâmetros às implicações do movimento antivacina, sobre os quais se entende que, além de estarem relacionados entre si, apontam fragilidades na estrutura social e necessitam ser aprofundados, dos quais: disseminação de informações e atribuições da Ciência na sociedade; e determinismo político-econômico em detrimento de uma formação crítica.

\subsection{Disseminação de informações e atribuições da Ciência na sociedade}

Segundo Succi (2018), as crenças e os argumentos dos movimentos antivacinas mantiveram-se inalterados pelos dois últimos séculos, no entanto, as novas mídias sociais facilitaram a disseminação de informações opostas às vacinas. A autora menciona que a nomenclatura em relação a esse assunto foi denominada pela Organização Mundial da Saúde como "hesitação vacinal", e complementa, mencionando que, um estudo de 2016, relacionado a percepções sobre segurança, eficácia e importância das vacinas - incluindo as crenças religiosas - indicou que, mesmo com uma alta confiança nas vacinas, alguns países da Europa apresentam respostas negativas a essas. Tais dados relacionam-se às formas como se tem acesso às informações atualmente, já que, com o avanço dos meios de comunicação, a quantidade de notícias diárias é crescente. Diante disso, é pertinente pensar a relevância e intencionalidade de tais informações para setores como indústria e sociedade em geral. 
Auler (2007) menciona que a ausência de discussões sobre essas intencionalidades contribui para perpetuar uma visão de superioridade/neutralidade atribuída à $C \& T$. Essas visões transformaram-se em senso comum, exercendo efeito paralisante com uma percepção ingênua da realidade. É relevante, portanto, refletir sobre como se tem acesso às informações e às visões vinculadas aos discursos ideológicos sobre $\mathrm{C} \& \mathrm{~T}$, que, neste estudo, diz respeito aos movimentos antivacinas. $\mathrm{O}$ autor alerta que a ausência de uma visão crítica coloca a realidade imobilizada, anestesiada pelo discurso pragmático, que inviabiliza, por exemplo, a análise das implicações da vacinação.

Sobre isso, Succi (2018) argumenta que o acesso às informações a respeito das vacinas difundidas nas mídias influencia a tomada de decisão sobre vacinar ou não. A autora alerta que as informações nem sempre são corretas, acarretando sentimentos conflitantes. A carência de informações legítimas ou o fato de não buscar informações verdadeiras, além de contribuir para disseminação de inverdades, têm impacto negativo, principalmente nas camadas da sociedade com baixa escolaridade. Por isso, a consciência e visão crítica são fundamentais no sentido de avaliar a procedência dos fatos e poder emitir opiniões.

A ausência dessa visão crítica impossibilita uma leitura da realidade, de modo que C\&T são consideradas em um viés utilitarista. Por isso, Auler e Delizoicov (2006) apontam a importância de processos formativos de professores que contemplem as relações CTS para qualificar a prática político-pedagógica e, dentre outras possibilidades de trabalho, apontam a problematização de C\&T portadoras de certezas, de respostas definitivas; e a tecnologia nem boa e nem ruim. Tudo depende do uso que se der a ela.

A inserção de discussões nesse sentido, em propostas educativas, vem sendo apontada mediante as CSC (FORGIARINI; AULER, 2009) como possibilidade de aprendizagem dos conteúdos conceituais, mas também de processos de natureza científica e tecnológica, bem como desenvolvimento cognitivo, social e ético dos estudantes. A abordagem de temas coerentes com a Educação CTS (GIACOMINI; MUENCHEN, 2016; ROSA; AULER, 2016) também é apontada como potencialidade nos processos educativos em que os estudantes podem pesquisar e selecionar fontes de informação, contrapondo pontos de vista na compreensão de problemas.

Os argumentos utilizados pelos movimentos antivacinas, muitas vezes, teoricamente, possuem embasamento científico ou abarcam termos técnicos, o que atribui certa credibilidade no repasse das informações. Esse aspecto, para Auler (2002), constitui o mito da perspectiva salvacionista atribuída à C\&T, haja vista que a Ciência é vista hegemonicamente como redentora de muitos saberes relevantes em nossa sociedade, sendo assim, a utilização do termo "cientificamente comprovado" possui alto grau de convencimento.

Em texto publicado em seu portal eletrônico a esse respeito, Conte (2017) menciona que têm ganhado força movimentos de oposição às vacinas. Tais movimentos, segundo o autor, utilizam argumentos que contradizem as evidências científicas mais elementares, pois defendem que as vacinas debilitam o organismo, comprometem o desenvolvimento do sistema imunológico, causam autismo, alergias e, ainda, retardo mental. Outro argumento utilizado é o de violação contra o corpo dos indivíduos, já que as campanhas de vacinação incentivam que se vacine desde os primeiros anos de vida. Dessa forma, os sujeitos estariam se submetendo às normas sanitárias. Essas informações ganham proporções maiores via mídias sociais e, em países europeus, é responsável por mais de sete mil casos de sarampo, doença que estava quase desaparecendo.

Diante disso, é importante perceber como e por quem se tem acesso às informações cotidianamente. Além disso, também parece ser de igual importância problematizar as visões 
atribuídas à Ciência e sua influência na tomada de decisão e escolhas a nível social, pois notícias distorcidas e/ou maquiadas podem interferir no bem-estar de muitas pessoas e, em se tratando do processo de vacinação, diz respeito a uma questão de saúde pública/coletiva.

\subsection{Determinismo político-econômico em detrimento de uma formação crítica}

O movimento antivacina também pode ser compreendido no contexto do sistema capitalista, que se movimenta e sobrevive essencialmente do capital. Segundo dados do Guia 2019, da Associação da Indústria Farmacêutica de Pesquisa (2019), o faturamento do mercado farmacêutico do Brasil em 2018 foi de R \$ 76,20 bilhões, sendo que, entre 2005 e 2018, a receita foi de R \$ 586,57 bilhões. Esse ganho movimenta uma grande porção de setores de produção e comercialização da área da saúde e, em termos de faturamento, mantém o mercado dos medicamentos sempre aquecido. Logo, o uso crescente de remédios não está relacionado apenas a uma questão social, enquanto saúde pública, mas também a aspectos econômicos e políticos. (In)diretamente, o surgimento e/ou volta de algumas doenças evitáveis por meio das vacinas contribuem para aumentar a busca por produtos que atenuem ou cessem os sintomas, da mesma forma que mobilizam a urgência de novas pautas de pesquisa, potencializando o faturamento. Pode-se dizer que esse aspecto, ainda que necessite de uma análise mais aprofundada sobre suas implicações na dimensão tecnológica, também reforça o discurso do movimento antivacina. Sobre isso, Auler (2018) menciona que o produto tecnológico materializa interesses e desejos de sociedades ou grupos sociais hegemônicos e, no caso de um possível movimento contrário às vacinas, alguns valores ligados à rentabilidade econômica podem estar relacionados.

O autor complementa que se ensina, tanto na Educação Básica quanto na universidade, justamente os valores internalizados desses aparatos tecnológicos, estendendo-se valores, práticas e conhecimentos comprometidos com a maximização do lucro privado, ou seja, cultivase ainda no ambiente escolar o modelo de sociedade capitalista. Por isso, o que se assume com as CSC, para além de uma mudança metodológica ou curricular, é o comprometimento com a relevância social, tratando de questões emergentes, sem pretensão de intencionar a formação de opiniões nem de se colocar em posição neutra, mas oportunizar espaços de discussões.

Outro aspecto que contribui, em certa medida, para intensificar a difusão de informações precipitadas/inconsistentes sobre as vacinas é a ausência de conhecimento sobre o processo de construção do conhecimento científico. Essa ausência pode estar relacionada, também, a uma ausência de um processo formativo que permita realizar uma leitura mais crítica sobre diversos acontecimentos. Acredita-se que a carência de práticas nesse sentido está internalizada no campo curricular, uma vez que, historicamente no Brasil, o papel do professor é de mero executor de currículos (AULER, 2011), não sendo sua função articular propostas curriculares.

A estruturação de currículos de caráter instrucional e apenas a execução por parte dos professores, para Auler (2011), é a cristalização da lógica tecnocrática nos currículos. Nesse entendimento, os conteúdos são o foco do processo de aprendizagem, ficando excluídas dimensões sociais e históricas. Por isso, Delizoicov, Angotti e Pernambuco (2011, p. 34) argumentam que a "[...] produção de conhecimento que caracteriza a C\&T constitui uma atividade humana socio-historicamente determinada".

A falta da compreensão do processo histórico em práticas educativas é uma questão a ser discutida tanto na Educação Básica quanto na formação de professores, já que os docentes constituem papel fundamental na articulação de práticas de ensino. Em estudo anterior (FONSECA; DUSO, 2019), identificou-se que aspectos como a História da Ciência parecem estar ausentes ainda na formação inicial, o que influencia na compreensão do conhecimento 
científico enquanto produção social histórica e, consequentemente, na articulação de propostas que incluam essa dimensão. Por outro lado, também se pode dizer que essa falta de clareza sobre a produção do conhecimento científico é obstaculizada pela organização de um ensino tradicional, já que um currículo que busca potencializar a participação em debates sobre C\&T e temas sociais, de modo geral, é incoerente com uma concepção de ensino tradicional (AULER, 2011). Caminhos que têm demonstrado possibilidades consistentes na superação desse cenário consistem no trabalho em torno de temas, controvérsias, no trato com questões reais. Nessa possibilidade, os conteúdos, segundo Auler (2011), assumem o papel de "ferramentas culturais" que auxiliam a iluminar as discussões das controvérsias sob vários ângulos. Essa concepção destoa da perspectiva de educação enquanto reprodução e simples apropriação de conhecimentos.

Daí a importância de uma formação para cidadania, que seja crítica. No entanto, para Reis (2004), os conceitos ensinados na Educação em Ciências não dão conta de compreender todos os avanços tecnológicos, uma vez que estão em constantes modificações. Por isso, a utilização das CSC permite a discussão de aspectos relacionados a problemáticas reais, não se detendo apenas aos conceitos científicos, de forma estática, mas possibilitando buscar argumentos e utilizar os conteúdos para compreender determinadas questões, o que permite, também, estabelecer relações com aspectos sociais.

\section{Algumas considerações}

O movimento antivacina, que se intensificou devido à atuação de alguns grupos em mídias sociais, constitui, atualmente, uma problemática social relacionada a uma questão de saúde pública/coletiva. As informações difundidas sobre as vacinas acabam sendo absorvidas como verdades absolutas e são repassadas como conhecimentos válidos. Além de implicações sociais, informações favorecem a descrença na produção da comunidade científica. Por isso, apresenta-se, neste trabalho, o que se considera ser uma possibilidade de inserção de questões sociais em práticas educativas através das CSC. No âmbito das controvérsias, há a busca por informações e discussões de diferentes pontos de vista sobre um mesmo tema sem sobrepor opiniões ou realizar um simples juízo de valor.

No entanto, é importante não atribuir às CSC o simples papel de instrumento ou aporte metodológico para aprendizagem exclusiva de conhecimentos científicos. Além disso, a utilização das CSC não pode constituir-se em simples situações simuladas no contexto de sala de aula, mas em discussões que estejam relacionadas com a vida dos estudantes, em que dimensões sociais e políticas estão envolvidas.

Outrossim, algumas limitações, apontadas por Reis e Galvão (2004), na inserção das CSC precisam ser superadas no aprofundamento de temas em aula, no sentido de evitar reducionismos na abordagem de questões controversas, como o aprofundamento de estudos sobre o tema a ser trabalhado a fim de evitar simplificações e a necessidade de uma reflexão epistemológica sobre C\&T, admitindo a impossibilidade de adquirir respostas apenas a partir de conhecimentos científicos. Essas questões podem influenciar as discussões em torno das controvérsias, excluindo dimensões políticas e ambientais, por exemplo, em que os discursos científicos estão ausentes diante da interpretação da realidade e a consequente difusão de tais conhecimentos.

Enfim, espera-se que as discussões realizadas no presente trabalho possam contribuir em alguma medida para as ações realizadas em sala de aula no Ensino de Ciências. Ainda que os apontamentos tecidos tenham dimensão teórica, refletem aspectos de dimensão social, 
importantes de serem problematizados nos processos educativos. Espera-se, portanto, que a inserção de temáticas relacionadas à realidade do estudante, em diferentes níveis (local, regional, global), seja um elemento relevante na articulação de práticas educativas, tanto por meio das CSC e CTS quanto por meio de outras propostas temáticas, para que possam superar cenários como a desmotivação dos estudantes, a falta de considerações sobre o mundo real e a ausência de atitudes de participação.

\section{Referências}

ANGOTTI, J. A. P.; AUTH, M. A. Ciência e tecnologia: implicações sociais e o papel da educação. Ciência \& Educação, Bauru, v. 7, n. 1, p. 15-27, 2001. Disponível em: http://www.scielo.br/pdf/ciedu/v7n1/02.pdf. Acesso em: 22 out. 2019.

\section{ASSOCIAÇÃO DA INDÚSTRIA FARMACÊUTICA DE PESQUISA. Guia 2019. São}

Paulo: Interfarma, 2019. Disponível em:

https://www.interfarma.org.br/public/files/biblioteca/guia-interfarma-2019-interfarma2.pdf.

Acesso em: 02 dez. 2019.

AULER, D. Cuidado! Um cavalo viciado tende a voltar para o mesmo lugar. 1. ed. Curitiba: Appris, 2018.

AULER, D. Enfoque ciência-tecnologia-sociedade: pressupostos para o contexto brasileiro.

Ciência \& Ensino, São Paulo, v. 1, n. especial, nov. 2007.

AULER, D. Interações entre ciência-tecnologia-sociedade no contexto da formação de professores de ciências. 2002. Tese (Doutorado em Educação: Ensino de Ciências Naturais) - Programa de Pós-Graduação em Educação, Universidade Federal de Santa Catarina, Florianópolis, 2002. Disponível em: https://repositorio.ufsc.br/handle/123456789/82610. Acesso em: 19 abr. 2020.

AULER, D. Novos caminhos para a educação CTS: ampliando a participação. In: SANTOS, W. L. P. dos; AULER, D. (org.). CTS e educação científica: desafios, tendências e resultados de pesquisas. Brasília: Editora Universidade de Brasília, 2011. p. 73-97.

AULER, D.; DELIZOICOV, D. Ciência-Tecnologia-Sociedade: relações estabelecidas por professores de ciências. Revista Electrónica de Enseñanza de las Ciencias, [S. 1.], v. 5, n. 2, p. 337-355, 2006. Número extra.

BELTRAN, M. H. R.; SAITO, F.; TRINDADE, L. S. P. História da Ciência para formação de professores. São Paulo: Livraria da Física/Capes/Obeduc, 2014.

CONTE, J. Por que antivacinas optam por não imunizar seus filhos? In: PORTAL Drauzio Varella, [S. 1.], 2017. Disponível em: https://drauziovarella.uol.com.br/saudepublica/por-que-antivacinas-optam-por-nao-imunizar-seus-filhos/. Acesso em: 19 abr. 2020.

DELIZOICOV, D.; ANGOTTI, J. A.; PERNAMBUCO, M. M. Ensino de Ciências: fundamentos e métodos. São Paulo: Cortez, 2011.

DRIVER, R. et al. People's images of science. Buckingham and Philadelphia: Open University, 1996. 
DUSO, L. Discussões de controvérsias sociocientíficas e projetos integrados: perspectivas para o ensino de ciências. In: ENCONTRO NACIONAL DE PESQUISA EM EDUCAÇÃO EM CIÊNCIAS (ENPEC), 11., 2017, Florianópolis. Anais [...] Florianópolis: ABRAPEC, 2017. Disponível em: http://www.abrapecnet.org.br/enpec/xi-enpec/anais/resumos/R09811.pdf. Acesso em: 18 abr. 2020.

DUSO, L.; HOFFMANN, M. B. A discussão das controvérsias sociocientíficas na pesquisa em educação em ciências: uma revisão narrativa a partir de periódicos no Brasil. Ensino de Ciências e Tecnologia em Revista, Santo Ângelo, v. 3, n. 2, p.66-85, jul./dez. 2013.

Disponível em:

https://docs.google.com/viewerng/viewer?url=http://srvapp2s.urisan.tche.br/seer/index.php/en citec/article/viewFile/1125/528. Acesso em: 04 nov. 2019.

FONSECA, E. M.; DUSO, L. Entre crenças e aparências: compreensões sobre ciência por licenciandos em ciências da natureza. Revista Brasileira de Ensino de Ciência e

Tecnologia, Curitiba, v. 12, n. 2, 2019. Disponível em:

https://periodicos.utfpr.edu.br/rbect/article/view/7371. Acesso em: 19 abr. 2020.

FONSECA, E. M.; DUSO, L.; HOFFMANN, M. B. Discutindo a temática agrotóxicos: uma abordagem por meio das controvérsias sociocientíficas. Revista Brasileira de Educação do Campo, Tocantinópolis, v. 2, n. 3, p. 881-898, 2017. Disponível em:

https://sistemas.uft.edu.br/periodicos/index.php/campo/article/view/3814. Acesso em: 18 abr. 2020.

FORGIARINI, M. S.; AULER, D. A abordagem de temas polêmicos na educação de jovens e adultos: o caso do "florestamento" no Rio Grande do Sul. Revista Electrónica de Enseñanza de las Ciencias, Vigo, v. 8, n. 2, p. 399-421, 2009.

GIACOMINI, A.; MUENCHEN, C. Avanços alcançados por professores na implementação da abordagem temática em uma escola pública estadual do interior do RS. Educação em Revista, Belo Horizonte, v. 32, n. 3, p. 189-216, jul./set. 2016.

MATTOS, R. L. P. Revolta da Vacina (1904): varíola e vacinação. In: COLÓQUIO DO LABORATÓRIO DE HISTÓRIA ECONÔMICA E SOCIAL (LAHES), 1., 2005, Juiz de Fora. Anais [...] Juiz de Fora: UFJF, 2005. Disponível em: http://www.ufjf.br/lahes/files/2010/03/c1-a60.pdf. Acesso em: 16 jan. 2020.

NELKIN, D. Science controversies: the dynamics of public disputes in the US. In: S. JASANOFF, S.; MARKLE, G.; PETERSEN, J.; PINCH, T. (org.). Handbook of science and technology studies. Thousand Oaks: Sage, 1995. p. 444-456.

PENIDO, A. Cresce $18 \%$ número de casos de sarampo no Brasil. In: MINISTÉRIO da Saúde. Brasília, DF, 2019. Disponível em: http://saude.gov.br/noticias/agencia-saude/45750cresce-18-numero-de-casos-de-sarampo-no-brasil. Acesso em: 06 jan. 2020.

PEREZ et al. A Abordagem de questões sociocientíficas no ensino de Ciências: contribuições à pesquisa da área. In: ENCONTRO NACIONAL DE PESQUISA EM EDUCAÇÃO EM CIÊNCIAS (ENPEC), 8., 2011, Campinas. Atas [...] Campinas: ABRAPEC, 2011.

Disponível em: http://www.nutes.ufrj.br/abrapec/viiienpec/resumos/R1606-1.pdf. Acesso em: 27 dez. 2019. 
PORTO, M. Y. Uma revolta popular contra a vacinação. Ciência e Cultura, São Paulo, v. 55, n. 1, jan./mar. 2004.

PORTO, M. Y. Uma revolta popular contra a vacinação. Ciência e Cultura, São Paulo, v. 55, n. 1, jan. 2003. Disponível em:

http://cienciaecultura.bvs.br/scielo.php?script=sci_arttext\&pid=S0009-

67252003000100032\&lng=en\&nrm=iso. Acesso em: 23 jan. 2020.

RAMOS, M. B.; SILVA, H. C. Controvérsias científicas em sala de aula: uma revisão bibliográfica contextualizada na área de ensino de ciências e nos estudos sociológicos da ciência \& tecnologia. In: ENCONTRO NACIONAL DE PESQUISA EM EDUCAÇÃO EM CIÊNCIAS (ENPEC), 6., 2007, Florianópolis. Anais [...] Florianópolis: ABRAPEC, 2007. Disponível em: http://fep.if.usp.br/ profis/arquivos/vienpec/CR2/p928.pdf. Acesso em: 27 dez. 2019.

REIS, P. Controvérsias sócio-científicas: discutir ou não discutir: percursos de aprendizagem na disciplina de ciências da terra e da vida. 2004. Tese (Doutorado em Educação) - Programa de Pós-Graduação em Educação, Universidade de Lisboa, 2004. Disponível em: https://repositorio.ul.pt/handle/10451/3109. Acesso em: 16 jan. 2020.

REIS, P; GALVÃO, C. The impact of socio-scientific controversies in Portuguese natural science teachers' conceptions and practices. Research in Science Education, [S. 1.], v. 34, n. 2, p. 153-171, 2004.

ROSA, S. E.; AULER, D. Não neutralidade da Ciência-Tecnologia: problematizando silenciamentos em práticas educativas CTS. Alexandria: Revista de Educação em Ciência e Tecnologia, Florianópolis, v. 9, n. 2, p. 203-231, nov. 2016.

SANTOS et al. A abordagem de questões sociocientíficas no ensino de ciências: uma compreensão das sequências didáticas propostas por pesquisas na área. In: ENCONTRO NACIONAL DE PESQUISA EM EDUCAÇÃO EM CIÊNCIAS (ENPEC), 8., 2011, Campinas. Anais [...] Campinas: ABRAPEC, 2011. Disponível em:

http://www.nutes.ufrj.br/abrapec/viiienpec/resumos/R0847-1.pdf. Acesso em: 27 dez. 2019.

SCLIAR, M. Oswaldo Cruz \& Carlos Chagas: o nascimento da ciência no Brasil. São Paulo: Odysseus, 2002.

SEVCENKO, N. A Revolta da Vacina: mentes insanas em corpos rebeldes. São Paulo: Scipione, 2003.

SUCCI, R. C. M. Vaccine refusal: what we need to know. Jornal de Pediatria, Rio de Janeiro, v. 6, n. 94, p. 574-581, 2018. Disponível em: http://www.scielo.br/pdf/jped/v94n6/pt_0021-7557-jped-94-06-0574.pdf. Acesso em: 27 dez. 2019.

Recebido em março de 2020.

Aprovado em maio de 2020. 